11. Necrobia rufipes DeGeer.

Clerus rufipes DeG. Mémoires pour servir à l' Histoire des Insectes, V, 1775, p. 165, pl. XV, fig. 4.

This cosmopolitan species was taken at Santarem, Itacoatiara, Porto Velho and Madeira-Mamoré R. R. Camp No. 39.

\title{
THE DEVELOPMENT OF THE MOUTHPARTS IN THE HOMOPTERA, WITH OBSERVATIONS ON THE EMBRYO OF SIPHANTA.
}

\author{
By F. Muir and J. C. Kershaw, \\ Honolulu, Hawaii.
}

The Revolution of the Embryo.

The following observations were undertaken to see whether the development of the head of a Homopteron was similar to that of a Heteropteron and to observe if the "mandibular plate" of certain authors was of mandibular origin or not. As certain early embryonic stages present features of interest we have included a short description of them.

The eggs of Siphanta acuta are long, cylindrical, flattened on the ventro-anterior surface where the micropylar area is situated, pointed at the anterior and rounded at the posterior end. The chorion of the eggshell bears the more or less hexagonal honeycomb impression of the follicle cells (epithelium) of the ovaries. The micropylar area appears to be a modification of this hexagonal pattern, where the (apparent) cell-walls are more crowded together and thus narrowed. The eggs are laid in batches of about 60 with the ventral surface uppermost, one overlapping the other so that, except the last layer, only the micropylar area is exposed. They are glued together with colleterial fluid and are difficult to get asunder without injury to the egg. The nymph, with the aid of an egg-burster, cuts a straight slit down the centre of the micropylar area to escape.

Twenty-four hours after the egg is laid, the blastoderm is distinct and a thickening along the dorso-posterior area indicates the primitive streak. At about the thirtieth hour the posterior end 
of the primitive streak begins to invaginate (Fig. 6, $a i$.) and is entirely invaginated about the fourtieth hour (Fig. 7); the amniotic cavity then closes. The embryo now lies on the dorsal side of the amniotic cavity (Figs. 7 and 8) with its caudal extremity towards the anterior and its cephalic extremity towards the posterior end of the egg; its ventral surface is turned towards the ventral aspect of the egg. In this position the embryo develops until about the fifth day when the revolution of the embryo takes place; a caudal flexure occurs as the embryo increases in size.
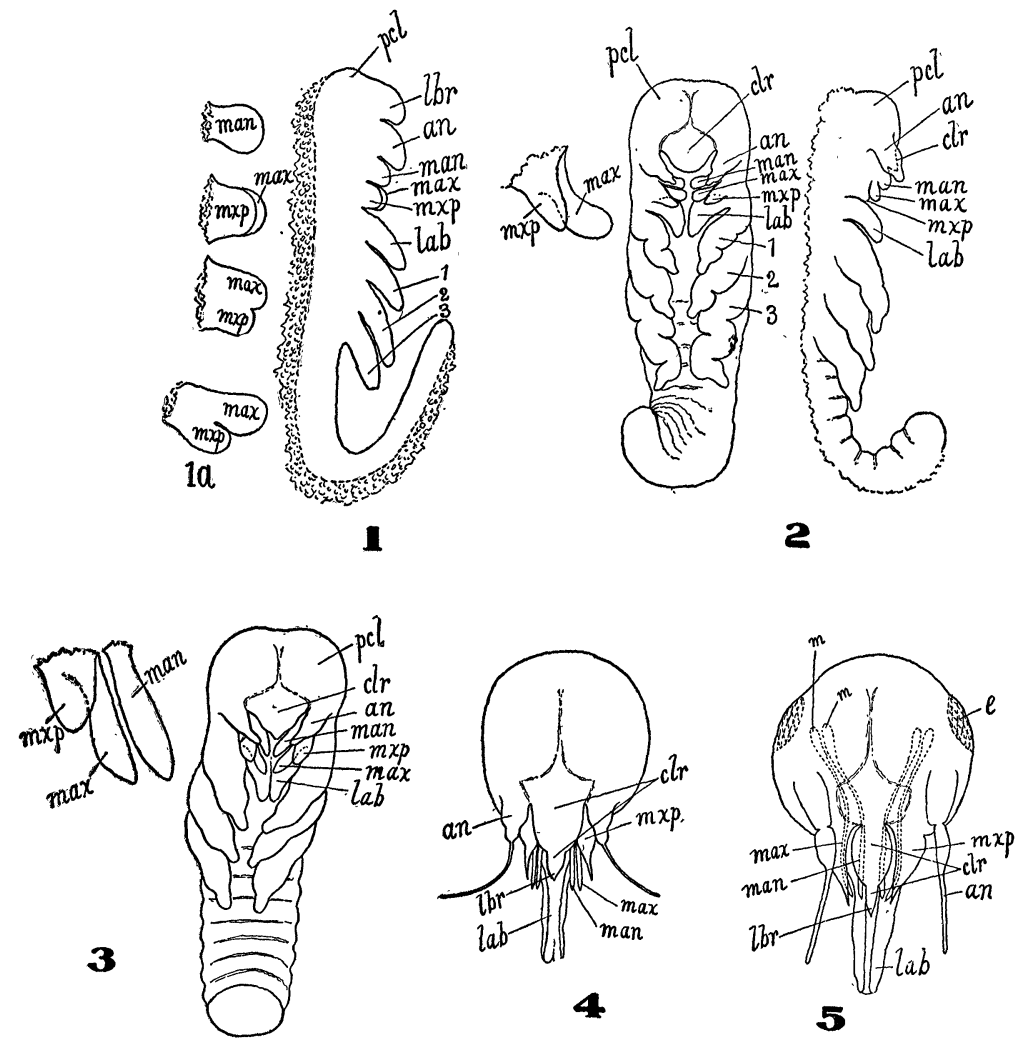

1. Lateral view of embryo on $2 \mathrm{~d}$ day.

1a. Side and front view of maxilla and mandible, $3 \mathrm{~d}$ day.

2. Front and side view of embryo on 4th day, with detached maxilla.

3. Front view of embryo of 5 th day, with detached maxilla and mandible.

4. Front view of head of embryo, 6 th day.

5. Front view of head of embryo, 10 th day. 

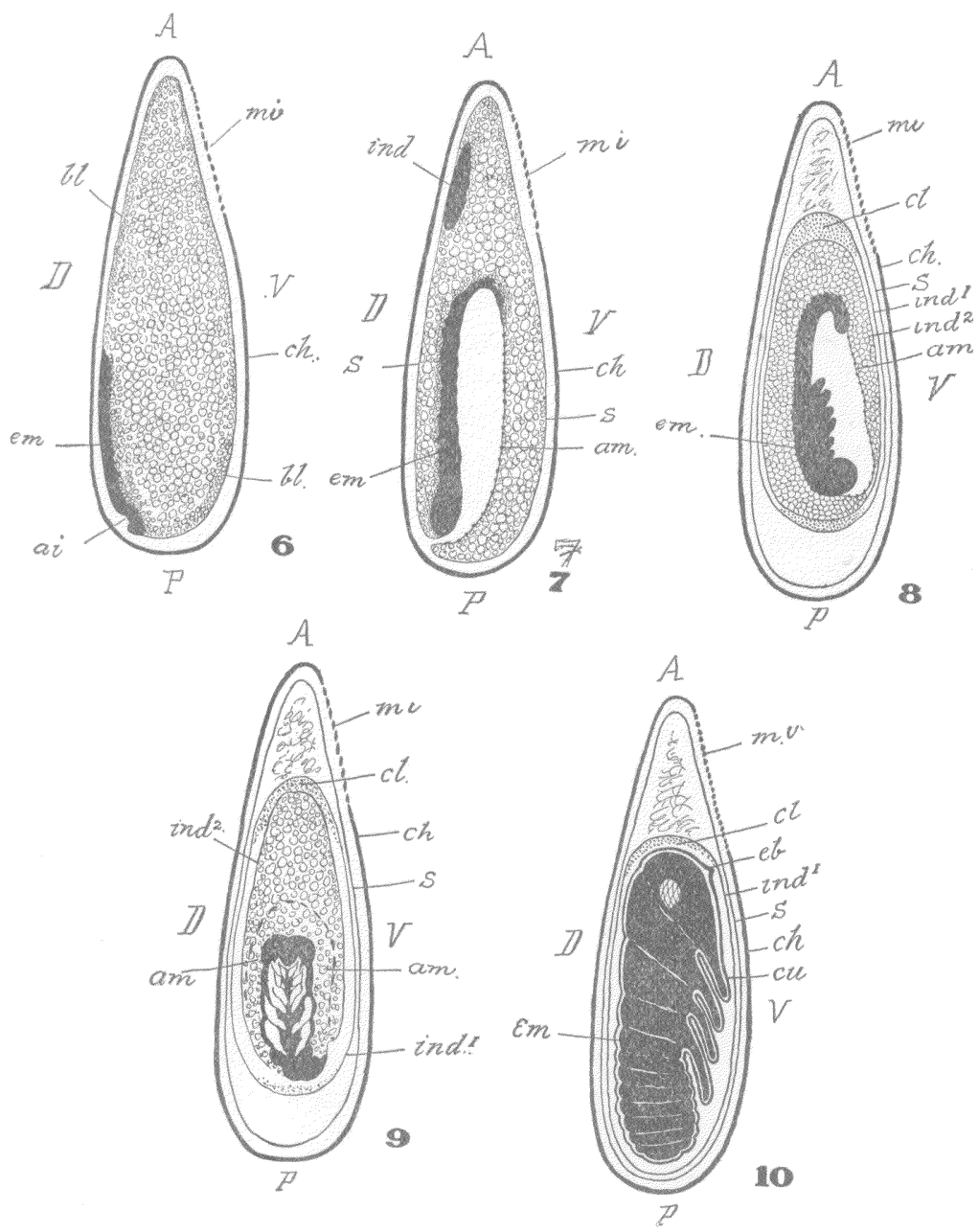

6. Lateral diagram of egg, about 30 hours; 7 , same, about 40 hours; 8 , same, about 4 days; 9 , same, about 5 days; 10 , same, about 12 days.

On the second day, before the amniotic cavity has closed, an "indusial thickening" appears on the antero-dorsal area of the blastoderm, similar to that described by Wheeler in Xiphidium (Fig. 7, ind.). We have not followed the development of the indusia in detail, but two are formed which entirely surround the egg beneath the serosa. The outer indusium (Figs. 8-10, ind. 1) be- 
comes closely applied to the serosa, except at the two poles, and remains intact until the hatching of the nymph; the inner indusium (Figs. 8-9, ind. 2) joins to the amnion near the head of the embryo and takes on the usual functions of the serosa during the revolution of the embryo. Between the fifth and sixth day the amnion (and the inner indusium) breaks open near the head of the embryo and the revolution commences. The head of the embryo leaves the amniotic cavity and moves upward to the dorsal side of the egg, towards the original position of the primitive streak; but when the head is well round to the dorsal side, the entire embryo, including the amnion and inner indusium, begins to revolve round the longitudinal axis of the egg, the revolution from the amniotic cavity continuing at the same time (Fig. 9) until the embryo lies on the ventral side of the egg in the normal position of insects during the later stages of embryonic development.

An embryonic cuticle covers the embryo, entirely sheathing all its members; a thickening of the cephalir portion of this cuticle forms the "egg-burster." Thus the mature embryo is enveloped in three coverings, apart from the chorion, viz.: The serosa (Fig. 10s), forming the outermost covering, the outer indusium (Fig. 10, ind $d^{1}$.) and the "embryonic cuticle" (Fig. 10, cu). The latter is generally referred to as the amnion, but there is little probability of the amnion having anything to do with its origin. In fact we question whether the amnion enters into the final membrane enveloping the adult embryo of Hemiptera (and perhaps all insects). The growth of the amnion over the ventral surface of the embryo has not been demonstrated; and the only other way for it to envelope the embryo would be by "substitution" (by disintegration and reformation over the surface of the embryo).

\section{The Development of the Trophi.}

A comparison of the development of the embryonic head of Siphanta to that of Pristhesancus ${ }^{1}$ demonstrates that they are fundamentally identical and that the differences that arise are due to the secondary developments of the head-capsule and its relative position to the thorax.

\footnotetext{
${ }^{1}$ Muir, F. and J. C. Kershaw. On the later embryological stages of the head of Pristhesancus papuensis. Psyche, Vol. 18, No. 2, (1911).
} 
2d day. (Fig, 1). On the second day the embryo is invaginated and lies on the dorsal side of the amniotic cavity and faces the ventral side of the egg, the head pointing posteriorly. The trophi and legs are fairly well developed, the clypeo-labrum being a median (apparently undivided) prominence of the cephalic lobes, forming the dorsal boundary of the oral cavity. The mandibles are plain, round, undivided processes or protuberances (man) forming - together with the maxillæ - the lateral boundaries of the oral cavity. The maxillæ already have a constriction indicating their future development into the maxillary plate ( $\operatorname{map}$ ) and the maxillary setæ (Max). The labrum (forming the ventral boundary of the oral cavity) is divided from its base and is very similar to a pair of legs. The abdomen is not distinctly segmented, is very long and ventrally flexed towards the head.

$3 d$ day. The protuberance forming the clypeo-labrum has bebecome somewhat pointed in the middle and the constrictions between the maxillary-setæ and maxillary-plates have further deepened (Fig. 1a). The abdomen has become more compact.

4th day. (Fig. 2). The procephalic lobes and clypeo-labrum have come forward, and the maxillary setæ and maxillary plates are well developed. The joints of the legs are indicated and the abdomen is fully segmented.

5th day. (Fig. 3). The clypeo-labrum is further developed and the labrum is indicated. The trophi have largely developed, the legs are not much altered but the labrum has begun to coalesce at the base. Between the 5th and 6 th day the revolution of the embryo takes place.

6th day. (Fig. 4). The embryo is now in its final position, its ventral side towards the ventral aspect of the egg and its head pointing anteriorly (Fig. 10). The distal joint of the antenna has thinned and lengthened remarkably; the labrum is differentiated from the clypeal region; the mandibles and maxillary setæ are long, pointed rods. The maxillary plates and the pharynx and clypeus have grown forward still more, forming between them the sulci in which the setæ lie. The labrum has wholly coalesced except at the tip, the edges have begun to turn up to form a trough, and the joints are discernable.

7th and 8th days. There is nothing striking to record.

9th day. The eyes are beginning to pigment, the edges of the 
labrum are quite turned up and over to form a trough, and the tip has also coalesced. From this stage onward to the hatching of the nymph, the various parts differ little from the adult, in which, however, the lines indicating the egg-burster, discernable since the third day, are not present. The basal portions of the setæ in the latter embryonic stages project slightly into the thorax as in the Heteroptera. On account of the comparative shortness of the setæ in Siphanta the basal portion is merely curved into the shape of the figure 6 , and is nearly all contained within the head.

\section{Nymphal Head of Cicada.}

In the nymph of Cicada, which appears to be less specialized than Siphanta, we found the relations of the setæ to the headcapsule clearly defined, and the key to the head of Siphanta.

In the head of Cicada there are three longitudinal sulci on each side. The first and most dorsal of these commences near the eye and, gradually deepening, runs anteriorly where it fuses with the lateral edges, and forms the main support of the pharynx. We call this the pharyngeal sulcus (Fig. 11 phc) and the pillar formed by its junction with the anterior-lateral edges of the pharynx the pharyngeal strut. (Fig. 11, pst). The second commences a little posterior to the pharyngeal sulcus and, rapidly deepening, runs anteriorly to the point of articulation of the mandibles; we call it the mandibular sulcus (Fig. 11, mdc.). The third, which we term the maxillary sulcus, divides the maxillary plate from the gular region. It runs round and joins the mandibular sulcus beneath the maxillary plate which projects as a free plate from between these two sulci. By lifting up the maxillary plate the setæ can be seen attached to the membrane at the junction of these two sulci. The walls of these sulci, especially in the adult, are closely applied together and have the appearance of being solid plates projecting into the head and have been so described; they have also been described as the tentorium. That this latter opinion is incorrect is seen by the fact that the tentorium exists in its normal condition and is formed by three pairs of invaginations. The largest of these invaginations is in the gular region, at the base of the maxillary sulci, and appears as a part of it; it joins the corresponding invagination from the opposite side and forms 
a large cross-bar. The second invagination arises from the posterior end of the mandibular sulci and, amalgamating with one from the antennal ring, joins the cross-bar near its origin.

The maxillary setæ arise from the base of the inner surface of the maxillary plate, a position they hold in the embryo after their division into two parts. The tendons (Fig. 11, $m x t$.) which support the retractor and protractor muscles (Fig. $11 \mathrm{rm} \mathrm{2,} \mathrm{pm} \mathrm{2)} \mathrm{arise}$ as all such internal chitinous structures arise, by the invagination

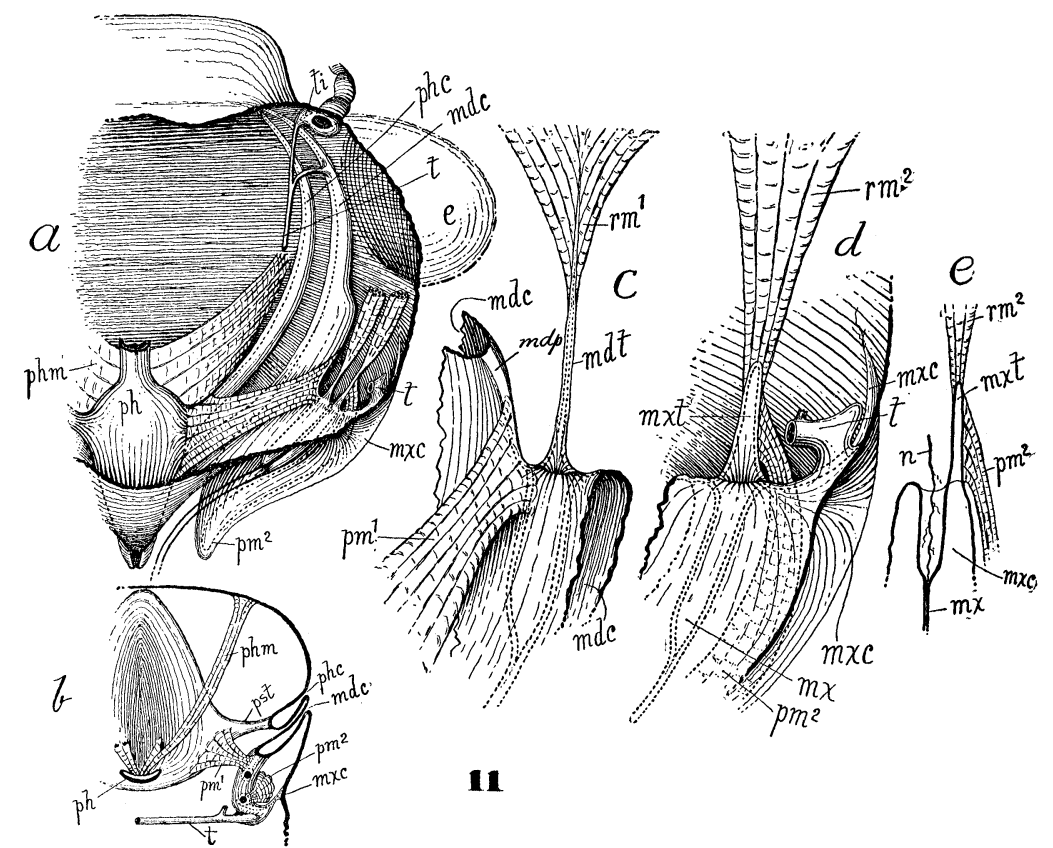

11a. Internal view of right side of head of nymphal Cicada.

11b. Horizontal section through head above pharynx.

11c. Attachment of mandibles to head-capsule.

11d. Attachment of maxillary seta to head-capsule.

11e. Sectional diagram of maxillary seta showing nature of chitinous "tendon."

of the ectoderm at the base of the setæ which becomes solid or partly solid by deposits of chitin (Fig. 11,e). These are often described as the basal parts of the maxillary setæ and have led to the idea that the setæ are drawn back into the head and have partly become internal organs. 
The mandibles are articulated at the anterior ends of the mandibular sulci. There is a thickening of the chitin of the walls of the mandibular sulci from the point of articulation to some distance posteriorly to which the protruder muscles are partly attached. This thickening we term the mandibular pillar (Fig. 11, $C m d p)$. It plays an important rôle and its homology in the more highly modified forms is difficult to recognize, but its origin can be easily discerned in the Cicada nymph. The tendons to which the retractor muscles (Fig. 11, $m d t$ and $r m$ 1) are attached have a similar origin to that of the maxillary setæ, namely, to an invagination and chitinization of the ectoderm at the base of the setæ.

The position of the trophi of the head of the nymphal Cicada is thus seen to be very little modified in position; the tentorium is similar to that of other insects and arises from the usual invaginations. The greatest modification is in the shape of the headcapsule, the formation of the three pairs of sulci, the amalgamation of the maxillary plate to the head-capsule and the forward position of the labrum and pharynx. The sulci appear to be the outcome of the maxillary plates and head-capsule overlapping and enclosing the setæ.

\section{The Head of Siphanta acuta Walker.}

If we now compare the head of Siphanta acuta (Fig. 12) with that of the nymphal Cicada we can follow their homologies. In Cicada the head-capsule is short and broad, the eyes being nearly on a level with the vertex; in Siphanta the head is long and narrow and the vertex prolonged far beyond the eyes. Incidentally we may state that a large "food-reservoir" (Fig. 12, fr) (a diverticulum from the œsophagus and crop) fills the epicranium of Flata in a similar manner to Pyrops candelaria.

The pharyngeal sulci are near the median line of the clypeal region, short, but project inward as long pharyngeal struts to the antero-lateral edges of the pharynx; the pharyngeal struts also give support to the protractor muscles of the mandibles. The sections (Fig. 14, $f$ pst) show a distinct lumen but actually the walls are so pressed together as to practically form a single plate. The walls do not, however, fuse; the invaginations can easily be 
pulled out flat with the rest of the clypeal region. The whole of this part is thus one piece and undivided.

The mandibular sulci (Fig. 12, $m d c$ ) start somewhat below the antennæ, extending in a curved line to the articulation of the mandibles where they meet the maxillary sulci at the base and inner side of the maxillary plates. From the point of articulation of the mandibles to the anterior end of the mandibular sulci, the
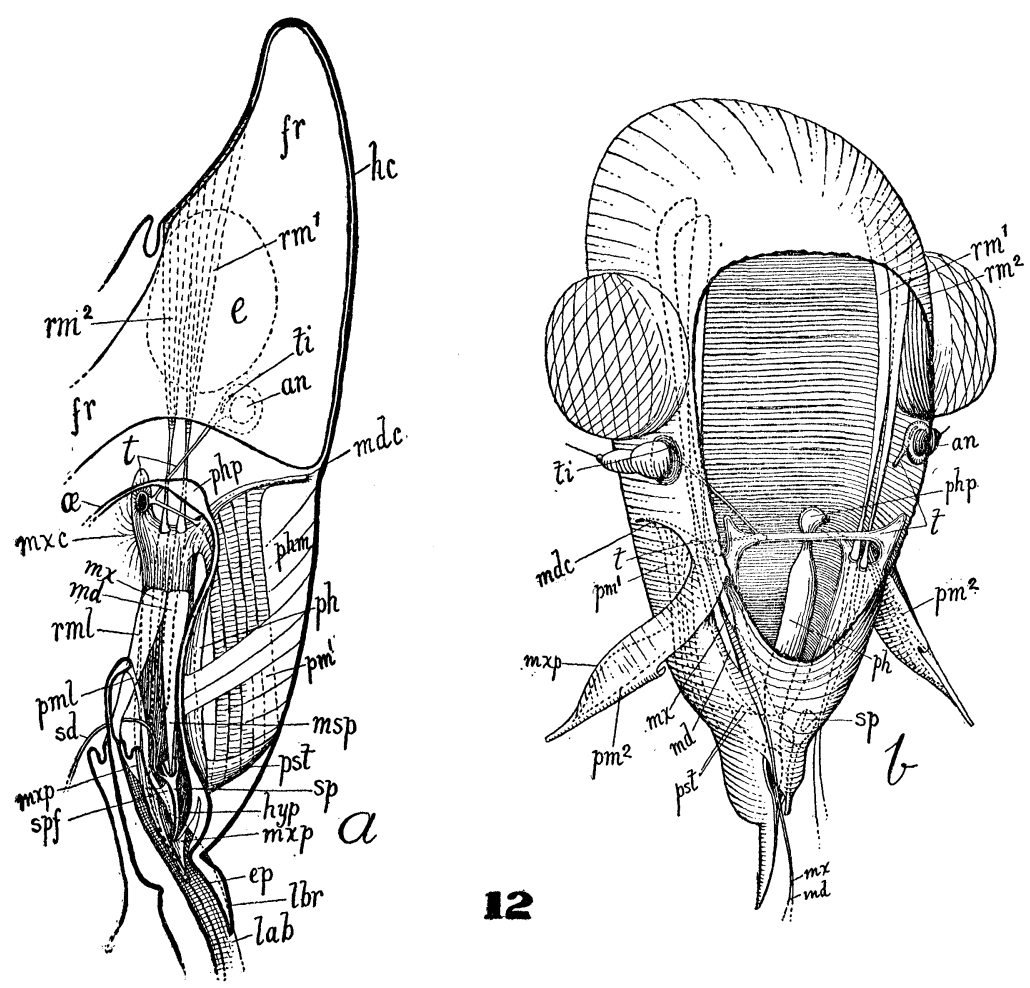

12a. Vertical median section through head of Flata.

12b. Hind view of skeleton of head of Flata.

bottoms of the sulci are chitinized to form the mandibular pillars. Owing to the delicacy of the rest of the sulcal membrane the mandibular pillars appear as rods projecting from the clypeal region, to which the mandibles are articulated. The thinning of this intermediate part of the sulci allows of a freer movement of the 
pillars and mandibles. The protractor muscles are attached to the mandibular pillars.

In the former paper we called the base of the mandibular pillar the point of articulation of the mandibles, which is morphologically incorrect but functionally correct. The tendons to which the retractor muscles are attached arise as invaginations at the base of the mandibles and are attached by muscles to the occiput; but they are so strongly chitinized in many forms that they appear as the basal portion of the mandibles and have led to the idea of the mandibles being drawn into the head-capsule.

The tentorium is the same as in Cicada. From the end of the maxillary sulcus arises an invagination which meets a similar invagination from the opposite side and forms the cross-bar; a slender invagination from the antennal ring joins the cross-bar near its origin, having just previously joined with the one from the mandibular sulcus. The fact that the principal branch of the tentorium arises from the bottom of the maxillary sulcus, the walls of which are pressed together and appear as one plate, has led to the idea that it (along with the mandibular sulcus) are parts of the tentorium.

The maxillary plate projects as a free body from between the ends of the maxillary and mandibular sulci, forming a cover for the setæ. The maxillary seta arises from the basal inner portion of the plate. A tendon arises from its base in a similar manner to that of the mandible and gives support to the retractor and protractor muscles, the former proceeding to the occupit, the latter to the distal portion of the maxillary plate (Fig. 11, $d$ and $e$ ).

The salivary syringe is attached by a flange to the back of the hypopharynx and opens at the distal end thereof. The syringe is a modified portion of the salivary duct.

While making the preceding studies it has appeared to the authors that the greatest difference between the head of Homoptera and the mandibulate insect lies in the amalgamation of the basal part of the maxilla to the head-capsule and its growth over the mandibles, along with the forward growth of the labrum and pharynx. The growth of the head-capsule necessary to bring about this change has resulted in the mandibular and maxillary sulci. The pharyngeal sulci appear to have been formed by the growth of the clypeal region whilst its anterior portion has been 
held fixed to the pharynx. The "mandibular plates" or loræ lie between the pharyngeal and mandibular sulci and are formed by them. They are not derived from the mandibles and have no relation whatever with them. The relative positions of the trophi have changed but slightly in spite of the great change of function.

Embryology shows us only that the maxillary plate is formed from the basal portion of the first maxilla and the seta from the distal portion. It is possible that the former represents the cardo and stipes and the latter the lacinia and galea combined, or the palpiger. That the palpus does not enter into the seta is evident

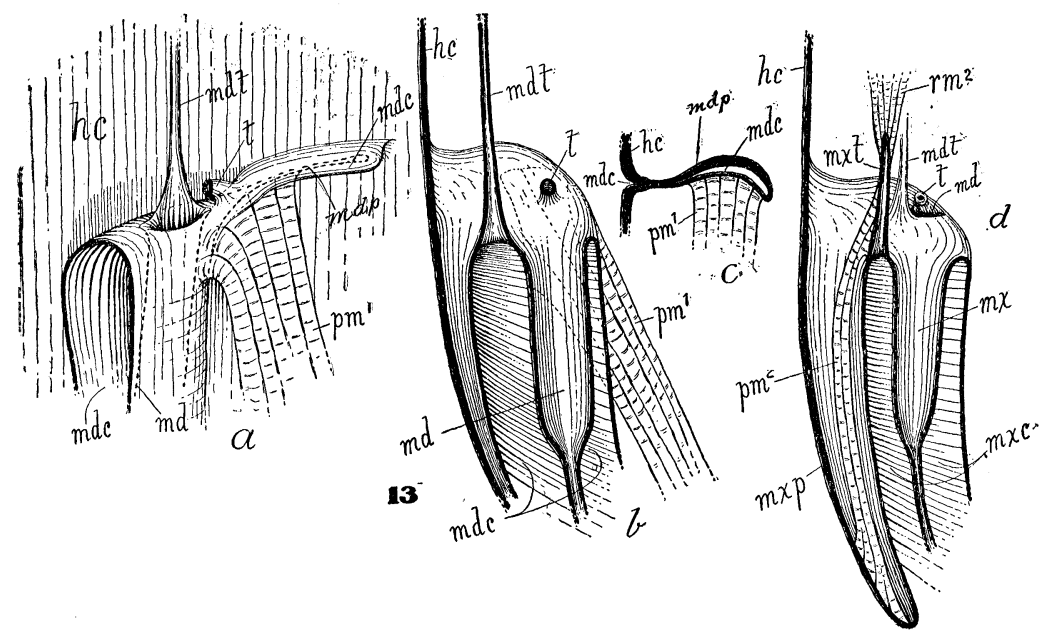

13a. Attachment of mandibles to head-capsule (Flata).

13b. Attachment of mandibles to head-capsule (section).

13c. Section through mandibular sulcus.

13d. Attachment of maxillary seta to head-capsule (section).

from the Thysanoptera having both seta and palpus. The two small lobes at the extremity of the maxillary plate in Thysanoptera may represent lacinia and galea, in which case the seta would most likely be a development of the palpiger, a conclusion one would be led to from its position.

The labrum is formed by the amalgamated second maxillæ and is homologous to the labrum of Thysanoptera. The similarity of the mouthparts of these two orders is not a superficial resemblance 
but a true homology, the mandibular pillar of Thysanoptera being formed in a similar manner, but the sulcus closes up more completely; the relationship of the maxillary seta to the maxillary plate is identical in the two orders. ${ }^{1}$

One of the latest works on the mouth-parts of Homoptera that we are acquainted with is the interesting memoire by $\mathrm{E}$. Bugnion and N. Popoff. ${ }^{2}$ These well-known savants have studied the subject from the adult stage and come to some slightly different conclusions than those reached by us from a study of the embryo.

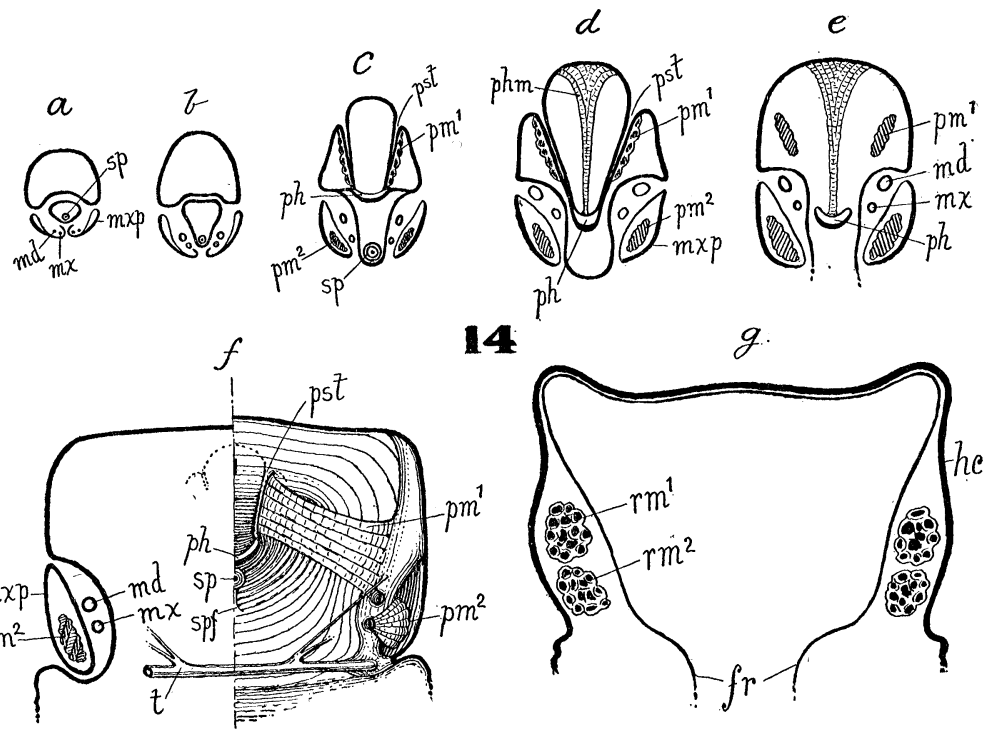

14a to g. Successive vertical sections through head of Flata; a, the most anterior; $\mathrm{g}$, the most posterior.

In conclusion we find that:

(1) The mandibles and maxillary arise as in other insects, the former being articulated in an approximately normal position.

(2) The Homopteran and Heteropteran mouthparts arise and develop in the same manner.

\footnotetext{
IIn a species of Thrips (Tubulifera) from Larat the young develop in the uterus of the female and are born fully developed. In some young embryos taken from a dried specimen of one of these there appears to be a seta on the right maxillary plate as well as on the left, which become aborted at a later stage. Our specimens were old and the evidence not reliable but the point is worth noting.

2Ann. Sci. Nat. 9e S. Zool. 1910.
} 
(3) There is no "mandibular plate."

(4) The tentorium agrees essentially with that of other insects.

(5) The maxillary seta does not represent the palpus, but may be a development of the palpiger or the combined lacinia and galea.

(6) The maxillary-plate represents the cardo and stipes.

\section{LETTERING OF FIGURES.}
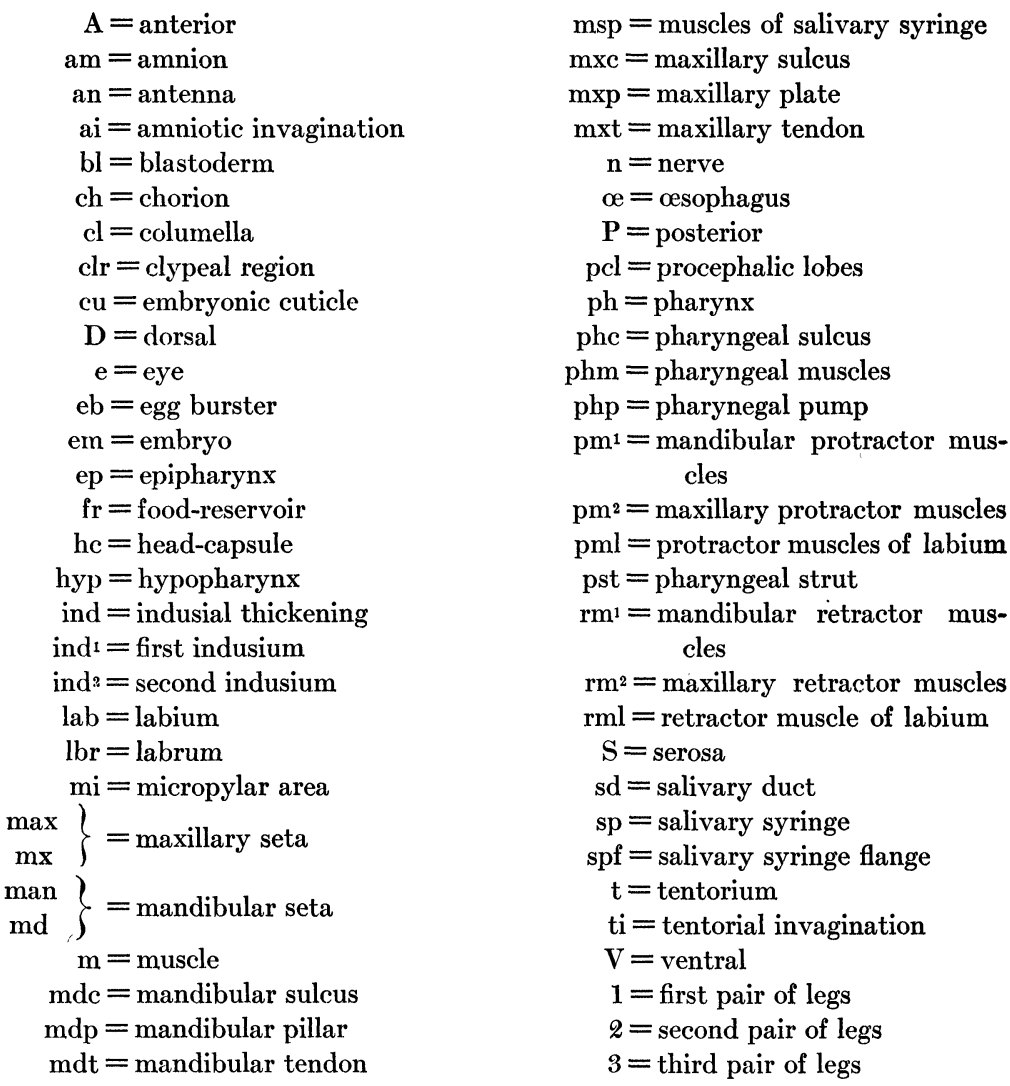

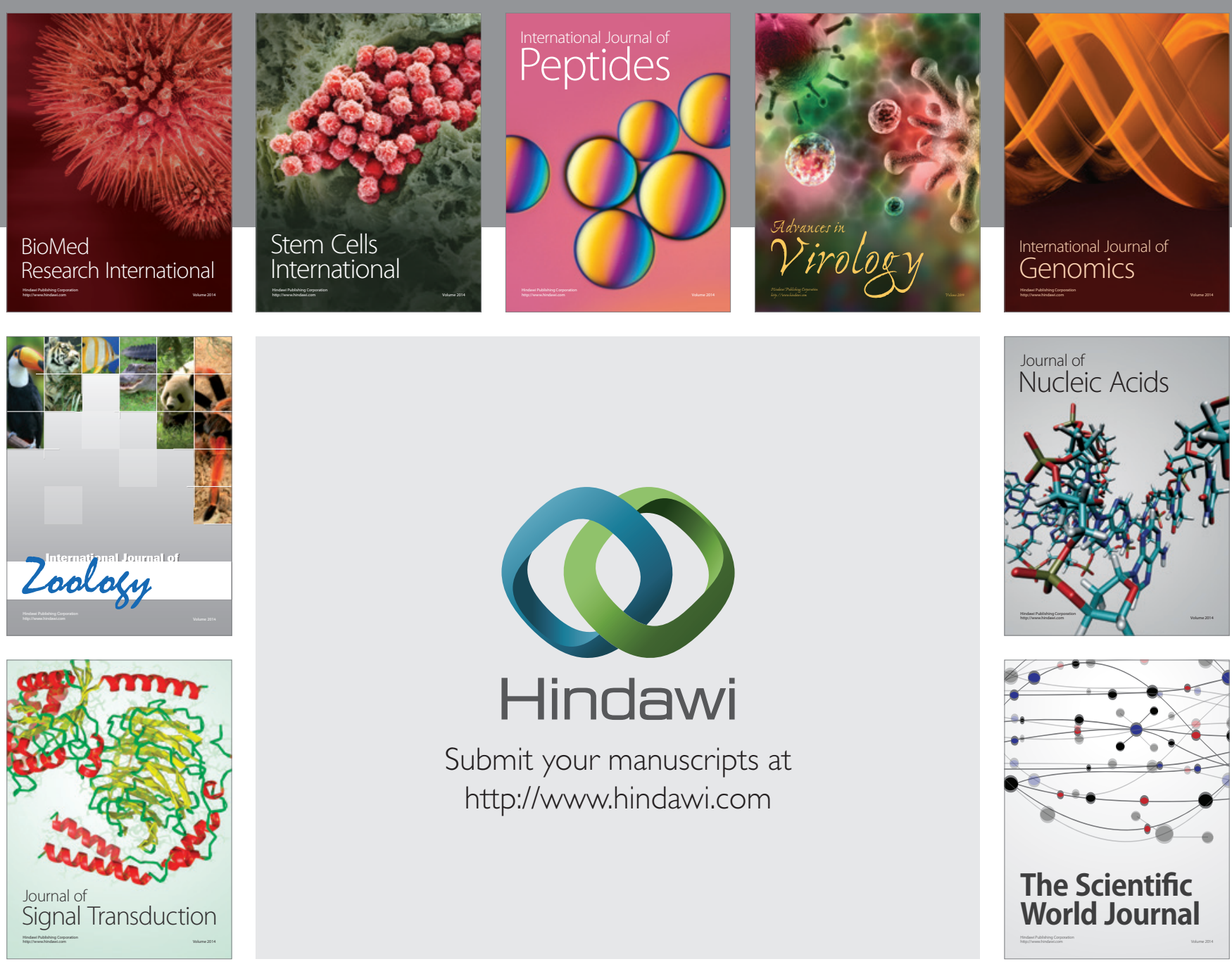

Submit your manuscripts at

http://www.hindawi.com
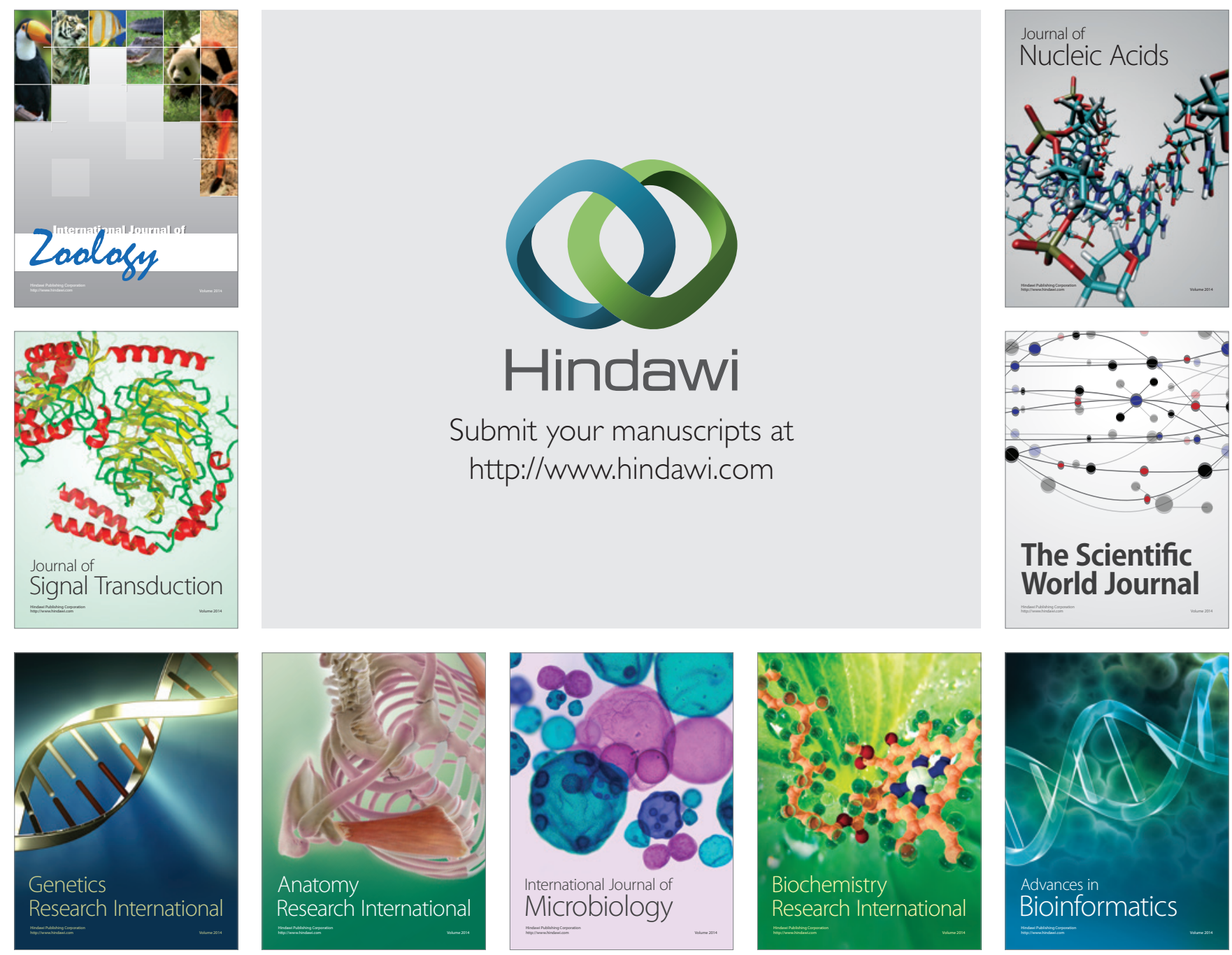

The Scientific World Journal
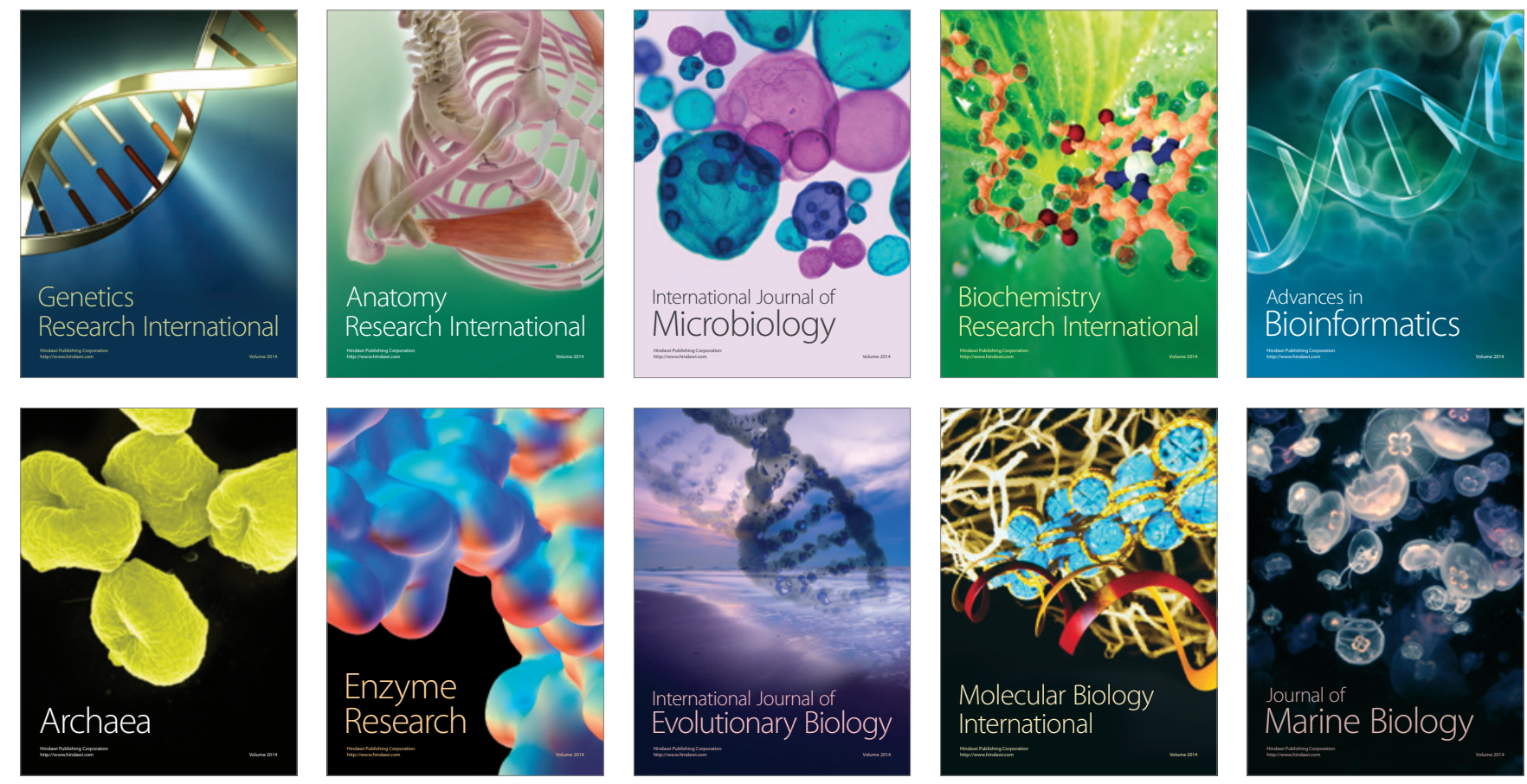